Original Article

\title{
Effect of life-space mobility on subjective well-being in aged home-based rehabilitation users with different levels of independence in activities of daily living
}

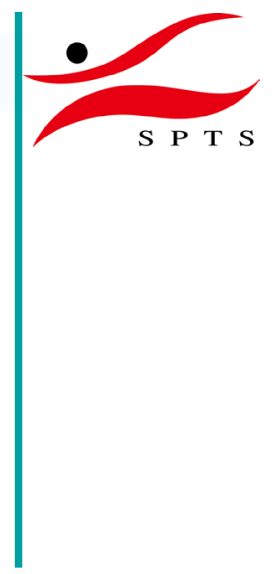

\author{
Yui Togashi, RPT ${ }^{1)}$, TAKaAki Fujita, OTR, $\mathrm{PhD}^{2)^{*}}$, TAKuro OHashi, OTR ${ }^{3)}$, \\ RYOHEI JinBO, RPT ${ }^{3)}$, RYUICHI KASAHARA, RPT, MS ${ }^{3)}$ \\ 1) Hobara Regional Comprehensive Support Center, Japan \\ 2) Department of Occupational Therapy, School of Health Sciences, Fukushima Medical University: \\ 10-6 Sakaemachi, Fukushima City, Fukushima 960-8516, Japan \\ 3) Department of Rehabilitation, Kita-Fukushima Medical Center, Japan
}

\begin{abstract}
Purpose] The relationship between quality of life and life-space mobility in community-dwelling older adults has recently been reported. The present study aimed to elucidate this relationship in home-based rehabilitation users with limited life-space mobility and loss of independence in activities of daily living. [Participants and Methods] The study population comprised 33 home-based rehabilitation users. The participants were expected to have a wide range of the level of independence in activities of daily living; therefore, they were categorized into three groups according to the Barthel Index score: independent (95-100 points), moderately disabled (90-65 points), and severely disabled (60-0 points) groups. We examined the relationships among the Philadelphia Geriatric Center Morale Scale, Life-Space Assessment, and Barthel Index scores and age. [Results] We detected a strong positive correlation between the Philadelphia Geriatric Center Morale Scale and Life-Space Assessment scores in the independent group; however, no significant correlations were observed in the moderately and severely disabled groups. [Conclusion] Our findings suggest a relationship between subjective well-being and life-space mobility in home-based rehabilitation users who are mostly independent in activities of daily living. However, owing to the small sample size and characteristics of the scales used in this study, further studies are warranted to verify these results.

Key words: Home-based rehabilitation, Life-space mobility, Subjective well-being
\end{abstract}

(This article was submitted Aug. 12, 2021, and was accepted Oct. 5, 2021)

\section{INTRODUCTION}

The main goal of rehabilitation is to improve patient quality of life (QOL) ${ }^{1)}$. Patients with chronic or late-stage sub-acute phase injuries are the main users of home-based rehabilitation, which aims to support participation and interaction with local communities, improve QOL, and maintain and improve mental and physical function and independence in activities of daily living (ADL). Therefore, clarifying the factors that affect the QOL of home-based rehabilitation users is essential for developing rehabilitation strategies.

Recent studies have reported a relationship between QOL and life-space mobility in community-dwelling older adults ${ }^{2-5}$. Based on these findings, we hypothesized that QOL and life-space are also related in home-based rehabilitation users. However, to the best of our knowledge, the relationship between the QOL and life space in home-based rehabilitation users has

*Corresponding author. Takaaki Fujita (E-mail: t-fujita@fmu.ac.jp)

(C2022 The Society of Physical Therapy Science. Published by IPEC Inc.

(c) (i) $(-)$ This is an open-access article distributed under the terms of the Creative Commons Attribution Non-Commercial No DerivaCC BY NC ND tives (by-nc-nd) License. (CC-BY-NC-ND 4.0: https://creativecommons.org/licenses/by-nc-nd/4.0/) 
not been investigated. Considering that life-space mobility is expected to differ between general community-dwelling older adults and home-based rehabilitation users with disabilities, the factors related to QOL may also differ between these groups. Therefore, it is necessary to investigate the relationship between QOL and life-space mobility in home-based rehabilitation users.

Reportedly, ADL is also considered as a factor associated with QOL in community-dwelling older adults and communitydwelling adults with disablities ${ }^{6-9}$. However, several studies found no significant relationship between QOL and ADL in community-dwelling adults with disabilities ${ }^{10-12)}$. Confounding results among previous studies ${ }^{6-12)}$ suggest that other factors affect the relationship between QOL and ADL. In other words, the degree of independence in ADL may affect QOL and interfere with other variables. Therefore, it was our understanding that it is necessary to stratify and analyze participants according to their degree of independence in ADL when analyzing the variables involved in QOL.

The purpose of this study was to clarify the relationship between QOL and life-space mobility in home-based rehabilitation users according to their ADL independence levels. Although various approaches can be used to assess QOL, we selected subjective well-being as an index, which is an important concept for measuring QOL in older adults.

\section{PARTICIPANTS AND METHODS}

This was a retrospective observational study. The participants were 33 home-based rehabilitation users (15 males and 18 females) who had no significant problems with visual, auditory, or cognitive function. As for the primary illness of the participants, stroke was 18 , orthopedic disease was 6 , neurodegenerative disease was 4 , others were 3 , and unknown was 2 participants. Regarding the long-term care insurance, "certified as requiring help 2" was 3 participants, and "Long-term care level 1, 2, 3, 4, and 5" were 4, 10, 3, 5, and 2 participants, respectively (Four participants used health insurance, and 2 participants were unknown). We assessed participants using the 17-item revised version of the Philadelphia Geriatric Center Morale Scale ${ }^{13}$ (PGCMS) as an index of subjective well-being, the Life-Space Assessment ${ }^{14,15)}$ (LSA) as an index of lifespace mobility, and the Barthel Index $\left.{ }^{16}\right)(\mathrm{BI})$ as an index of ADL. The content of this study was reviewed by the Institutional Review Board of the Kita-Fukushima Medical Center and approved for implementation (No. 88-2). Because the design of our study was retrospective without intervention, the opt-out method was used instead of informed consent.

PGCMS was designed to measure perceived morale in elderly individuals aged 70-90 years. The 17-item questionnaire consists of the following three factors: agitation, attitude toward own aging, and lonely dissatisfaction. Higher scores indicate better subjective well-being, and the highest possible score is 17 points. The LSA measures life-space mobility based on the spaces participants have used in the past 4 weeks in five areas as follows: outside their bedroom, outside their house, in their neighborhood, outside their neighborhood but within their town, and outside their town. Each life-space level is allocated a sub-score based on the average weekly frequency and independence of life-space mobility. The composite score ranges from 0 to 120 , with the higher scores representing greater mobility ${ }^{17)}$. The BI assesses self-care, such as feeding, transfer, grooming, toilet use, bathing, walking, climbing stairs, dressing, and bowel and bladder control, on a scale of 0 (full assistance) to 100 (full independence).

We classified participants into three groups based on their BI score as follows: independent group (BI 95-100 points), moderately disabled group (BI 90-65 points), and severely disabled group (BI score 0-60 points), referring to previous studies $^{18-21)}$. Differences in age, PGCMS, and LSA among groups were assessed using the Kruskal-Wallis test, and a post-hoc Mann-Whitney test with Bonferroni correction was performed for items that showed significant differences. Spearman's rank correlation coefficient was calculated to investigate the correlation between PGCMS and other variables within each group. SPSS Statistics version 25.0 was used for statistical analyses, and the level of significance was set at $\mathrm{p}<0.05$.

\section{RESULTS}

On the basis of their BI scores, 8 participants were categorized in the independent group, 14 in the moderately disabled group, and 11 in the severely disabled group. Table 1 shows the age, PGCMS, and LSA of participants in each group. Intergroup comparison revealed a significantly higher LSA in the independent group than the moderately and severely disabled groups $(\mathrm{p}<0.05)$. No significant intergroup differences in age and PGCMS were noted.

Table 2 shows the correlation coefficients between PGCMS and age, BI, LSA in each group. A strong positive correlation was found between PGCMS and LSA in the independent group ( $\mathrm{rs}=0.73, \mathrm{p}<0.05)$. No significant correlations were detected in the moderately and severely disabled groups.

\section{DISCUSSION}

Previous studies on community-dwelling older adults have suggested that QOL and life-space mobility are related ${ }^{2-5)}$. In this study, we investigated the relationship between QOL and life-space mobility in home-based rehabilitation users who are expected to have lower life-space mobility than general community-dwelling older adults. A previous study reported an average LSA score of 69.1 points in community-dwelling older adults ${ }^{3)}$. In contrast, the median LSA score in this study was very low at 20.0 points (even in the independent group, the median LSA score was 38.5 points). In a survey in Japan that 
Table 1. Age, PGCMS, and LSA by ADL independence group in this study participants

\begin{tabular}{|c|c|c|c|c|}
\hline & \multirow[b]{2}{*}{$\begin{array}{l}\text { Overall } \\
(\mathrm{N}=33)\end{array}$} & \multicolumn{3}{|c|}{ Activities of daily living } \\
\hline & & $\begin{array}{l}\text { Independence } \\
\qquad(\mathrm{N}=8)\end{array}$ & $\begin{array}{l}\text { Moderately disabled } \\
\qquad(\mathrm{N}=14)\end{array}$ & $\begin{array}{c}\text { Severely disabled } \\
(\mathrm{N}=11)\end{array}$ \\
\hline Age (years) & $75.0(70.0-80.0)$ & $72.0(64.5-84.0)$ & $74.0(70.0-80.0)$ & $75.0(71.5-81.5)$ \\
\hline PGCMS (points) & $11.0(8.0-13.0)$ & $9.0(7.5-14.0)$ & $12.0(8.0-13.0)$ & $12.0(8.0-13.0)$ \\
\hline LSA (points) & $20.0(14.0-34.0)$ & $38.5(28.0-44.8)^{* \dagger}$ & $16.0(14.0-22.0)^{*}$ & $20.0(10.5-22.0)^{\dagger}$ \\
\hline
\end{tabular}

Table 2. Correlation between the Philadelphia Geriatric Center Morale Scale and each item

\begin{tabular}{|c|c|c|c|c|}
\hline & \multirow[b]{2}{*}{$\begin{array}{l}\text { Overall } \\
(\mathrm{N}=33)\end{array}$} & \multicolumn{3}{|c|}{ Activities of daily living } \\
\hline & & $\begin{array}{l}\text { Independence } \\
\qquad(\mathrm{N}=8)\end{array}$ & $\begin{array}{c}\text { Moderate disabled } \\
(\mathrm{N}=14)\end{array}$ & $\begin{array}{c}\text { Severe disabled } \\
\qquad(\mathrm{N}=11)\end{array}$ \\
\hline Age (years) & -0.06 & -0.14 & 0.27 & -0.43 \\
\hline BI (points) & 0.04 & 0.23 & 0.11 & 0.50 \\
\hline LSA (points) & 0.20 & $0.73 *$ & -0.06 & 0.33 \\
\hline
\end{tabular}

Spearman's correlation coefficient with the Philadelphia Geriatric Center Morale Scale.

$* \mathrm{p}<0.05$.

BI: the Barthel Index; LSA: Life Space Assessment.

assessed LSA in individuals who were certified as requiring help, the average scores of those classified as "certified as requiring help 1" and "certified as requiring help 2" were 49.4 points and 42.6 points, respectively ${ }^{22}$ ). Therefore, the home-based rehabilitation users in this study have a particularly limited life-space compared with other groups.

We detected a strong positive correlation between PGCMS and LSA in the independent group. This result suggests that subjective well-being and life-space mobility are related in home-based rehabilitation users who were predominantly independent in ADL. Therefore, an approach that focuses on expanding life-space for home-based rehabilitation users who are mostly independent in ADL should be considered in addition to rehabilitation intervention focused on maintaining and improving mental and physical functions and ADL.

Alternatively, no correlations between PGCMS and LSA and BI were observed in the moderately and severely disabled groups in this study. In other words, we were unable to clarify the factors involved in the subjective well-being of home-based rehabilitation users with ADL difficulties. The abovementioned results were consistent with Kojima et al. ${ }^{2)}$, who found no significant correlation between subjective well-being (PGCMS) and ADL independence in home-based rehabilitation users. In home-based rehabilitation users requiring assistance with ADL, factors other than life-space mobility and ADL contribute to subjective well-being. In future research, additional measurement indices should be included to determine these factors.

This study has several limitations. First, our sample size was small; therefore, caution should be used when generalizing and interpreting the results. For example, in participants with a particularly low degree of ADL independence (BI $<65$ points), the correlation between PGCMS and BI was not statistically significant, but the correlation coefficient was 0.50 . Therefore, reexamination of these relationships using larger cohorts is necessary. Second, we did not limit participation in this study or collect data on participants' diseases, making it difficult to prevent additional influences from the characteristics of each disease. Diseases and related factors are likely to have significant impacts on subjective well-being, which should be considered in future studies. Third, in the LSA scale, points are added when participants attend regular care services, which could inflate scores even if participants do not want to leave their rooms or homes. Therefore, although this study clarified the relationship between subjective well-being and life-space mobility, it did not necessarily show the relationship between life-space mobility based on the participants' will and subjective well-being. Finally, the subjective well-being assessed in this study represents only one aspect of QOL. In the future, research to overcome the above limitations is warranted.

\section{Conflict of interest}

There are no conflicts of interest. 


\section{REFERENCES}

1) Tastekin N: Rehabilitation and quality of life in stroke patients. Turk J Phys Med Rehabil, 2015, 61: 97-98. [CrossRef]

2) Murata C, Kondo T, Tamakoshi K, et al.: Factors associated with life space among community-living rural elders in Japan. Public Health Nurs, 2006, 23: 324-331. [Medline] [CrossRef]

3) Bentley JP, Brown CJ, McGwin G Jr, et al.: Functional status, life-space mobility, and quality of life: a longitudinal mediation analysis. Qual Life Res, 2013, 22: 1621-1632. [Medline] [CrossRef]

4) Rantakokko M, Portegijs E, Viljanen A, et al.: Life-space mobility and quality of life in community-dwelling older people. J Am Geriatr Soc, 2013, 61: 1830-1832. [Medline] [CrossRef]

5) Rantakokko M, Portegijs E, Viljanen A, et al.: Changes in life-space mobility and quality of life among community-dwelling older people: a 2-year follow-up study. Qual Life Res, 2016, 25: 1189-1197. [Medline] [CrossRef]

6) Kim GM, Hong MS, Noh W: Factors affecting the health-related quality of life in community-dwelling elderly people. Public Health Nurs, 2018, 35: 482-489. [Medline] [CrossRef]

7) Niemi ML, Laaksonen R, Kotila M, et al.: Quality of life 4 years after stroke. Stroke, 1988, 19: 1101-1107. [Medline] [CrossRef]

8) Wyller TB, Sveen U, Sødring KM, et al.: Subjective well-being one year after stroke. Clin Rehabil, 1997, 11: 139-145. [Medline] [CrossRef]

9) Takemasa S, Shimada T, Hidaka M, et al.: Relationship among disablement, family functioning and QOL of the home-bound elderly with cerebrovascular accident. Rigakuryohogaku, 1996, 23: 137-140 (in Japanese).

10) Béthoux F, Calmels P, Gautheron V: Changes in the quality of life of hemiplegic stroke patients with time: a preliminary report. Am J Phys Med Rehabil, 1999, 78: 19-23. [Medline] [CrossRef]

11) Fuhrer MJ, Rintala DH, Hart KA, et al.: Relationship of life satisfaction to impairment, disability, and handicap among persons with spinal cord injury living in the community. Arch Phys Med Rehabil, 1992, 73: 552-557. [Medline]

12) Kojima K, Nakayama T, Watanabe A, et al.: Activities of daily living and quality of life assessment during home-based rehabilitation-a multi-institutional study. Jpn J Compr Rehabil Sci, 2017, 8: 30-36.

13) Lawton MP: The Philadelphia geriatric center morale scale: a revision. J Gerontol, 1975, 30: 85-89. [Medline] [CrossRef]

14) Parker M, Baker PS, Allman PM: A life-space approach to functional assessment of mobility in the elderly. J Gerontol Soc Work, 2002, 35: 35-55. [CrossRef]

15) Baker PS, Bodner EV, Allman RM: Measuring life-space mobility in community-dwelling older adults. J Am Geriatr Soc, 2003, 51: 1610-1614. [Medline] [CrossRef]

16) Mahoney FI, Barthel DW: Functional evaluation: The Barthel Index. Md State Med J, 1965, 14: 61-65. [Medline]

17) Johnson J, Rodriguez MA, Al Snih S: Life-space mobility in the elderly: current perspectives. Clin Interv Aging, 2020, 15: 1665-1674. [Medline] [CrossRef]

18) Samsa GP, Matchar DB: How strong is the relationship between functional status and quality of life among persons with stroke? J Rehabil Res Dev, 2004, 41 : 279-282. [Medline] [CrossRef]

19) Rozzini R, Sabatini T, Cassinadri A, et al.: Relationship between functional loss before hospital admission and mortality in elderly persons with medical illness. J Gerontol A Biol Sci Med Sci, 2005, 60: 1180-1183. [Medline] [CrossRef]

20) Carod-Artal FJ, Ferreira Coral L, Stieven Trizotto D, et al.: Self- and proxy-report agreement on the stroke impact scale. Stroke, 2009, 40: 3308-3314. [Medline] [CrossRef]

21) De Wit L, Putman K, Devos H, et al.: Five-year mortality and related prognostic factors after inpatient stroke rehabilitation: a European multi-centre study. J Rehabil Med, 2012, 44: 547-552. [Medline] [CrossRef]

22) Harada K, Shimada H, Sawyer P, et al.: [Life-space of community-dwelling older adults using preventive health care services in Japan and the validity of composite scoring methods for assessment]. Nippon Koshu Eisei Zasshi, 2010, 57: 526-537 (in Japanese). [Medline] 